\title{
Primary Intra-Arterial Chemotherapy for Retinoblastoma in the Intravitreal Chemotherapy Era: Five Years of Experience
}

\author{
Lauren A. Dalvin a, c Mamta Kumari ${ }^{a}$ Vera Adobea Essuman a, d \\ Shormin Shohelly Shipa ${ }^{a}$ David Ancona-Lezama ${ }^{a} \quad$ J. Antonio Lucio-Alvarez ${ }^{a}$ \\ Pascal Jabbour ${ }^{b}$ Carol L. Shields ${ }^{a}$ \\ ${ }^{a}$ Ocular Oncology Service, Wills Eye Hospital, Thomas Jefferson University, Philadelphia, PA, USA; \\ ${ }^{b}$ Department of Endovascular Neurosurgery, Thomas Jefferson University, Philadelphia, PA, USA; \\ 'Department of Ophthalmology, Mayo Clinic, Rochester, MN, USA; ${ }^{\mathrm{d} O p h t h a l m o l o g y}$ Unit, \\ Department of Surgery, School of Medicine and Dentistry, University of Ghana, Accra, Ghana
}

\section{Keywords}

Eye - Cancer - Retinoblastoma - Intra-arterial chemotherapy · Intravitreal chemotherapy

\begin{abstract}
Purpose: To report our 5-year experience with intra-arterial chemotherapy (IAC) in the intravitreal chemotherapy (IvitC) era. Methods: Retrospective review of retinoblastoma treated with primary unilateral IAC in the IvitC era (2012-2017). Results: There were 34 eyes treated with IAC alone versus 20 eyes treated with IAC plus IvitC for vitreous seeds. IAC (IAC alone vs. IAC plus IvitC) consisted of melphalan (41 vs. 10\%) or melphalan plus topotecan ( 59 vs. $90 \%, p=0.03$ ). IvitC consisted of melphalan (60\%) or melphalan plus topotecan (40\%). Tumor control and globe salvage were achieved in $100 \%$ of group B and C eyes without IvitC. Despite more extensive vitreous seeds in the IvitC group $(p<0.01)$, comparison of IAC alone versus IAC plus IvitC revealed no difference in tumor control for group $\mathrm{D}$ (88 vs. $69 \%, p=0.36$ ) or group $\mathrm{E}(67$ vs. $100 \%, p=0.25)$ and no difference in globe salvage for group D ( 88 vs. $69 \%, p=0.36$ ) or group $\mathrm{E}$ (58 vs. $57 \%, p=$
\end{abstract}

\section{KARGER}

(c) 2018 S. Karger AG, Basel

E-Mail karger@karger.com

www.karger.com/oop
0.39). Conclusions: IAC is effective as primary therapy for unilateral group $B, C, D$, and $E$ retinoblastoma. IvitC is an important adjuvant therapy to achieve comparable globe salvage rates for group $D$ and $E$ eyes with persistent active vitreous seeds.

(c) 2018 S. Karger AG, Basel

\section{Introduction}

Intra-arterial chemotherapy (IAC) has substantially improved globe salvage rates for eyes with moderate to advanced disease [1-6]. In a previous report of our 5-year experience with IAC by the International Classification of Retinoblastoma (ICRB) group, we found globe salvage rates of $100 \%$ for group B and C eyes, $94 \%$ for group D eyes, and $36 \%$ for group E eyes [2]. While IAC is effective for the majority of group B, C, and D eyes, the efficacy of IAC alone is limited in eyes with extensive vitreous seeds [1-6].

More recently, intravitreal chemotherapy (IvitC) has been found to be an effective adjuvant treatment for eyes with vitreous seeds [6-13]. In particular, globe salvage for 
Table 1. Patient demographics

\begin{tabular}{|c|c|c|c|c|}
\hline & $\begin{array}{l}\text { Primary IAC } \\
\text { alone } \\
(n=34)\end{array}$ & $\begin{array}{l}\text { Primary IAC } \\
\text { with IvitC } \\
(n=20)\end{array}$ & $p$ values & $\begin{array}{l}\text { Total patients } \\
(n=54)\end{array}$ \\
\hline Mean age at presentation, months & $17(13,2-59)$ & $50(36,5-278)$ & 0.02 & $29(18,2-278)$ \\
\hline \multicolumn{5}{|l|}{ Sex } \\
\hline Male & $21(62)$ & $13(65)$ & \multirow[t]{2}{*}{0.99} & $34(63)$ \\
\hline Female & $13(38)$ & $7(35)$ & & $20(37)$ \\
\hline \multicolumn{5}{|l|}{ Race } \\
\hline Caucasian & $21(62)$ & $14(70)$ & \multirow[t]{6}{*}{0.23} & $35(65)$ \\
\hline African American & $3(9)$ & $4(20)$ & & $7(13)$ \\
\hline Asian & $4(12)$ & $0(0)$ & & $4(7)$ \\
\hline Hispanic & $4(12)$ & $1(5)$ & & $5(9)$ \\
\hline Middle Eastern & $1(3)$ & $0(0)$ & & $1(2)$ \\
\hline Indian & $1(3)$ & $1(5)$ & & $2(4)$ \\
\hline \multicolumn{5}{|l|}{ Study eye } \\
\hline OD & $18(53)$ & $11(55)$ & \multirow[t]{2}{*}{0.55} & $29(54)$ \\
\hline OS & $16(47)$ & $9(45)$ & & $25(46)$ \\
\hline \multicolumn{5}{|l|}{ Laterality } \\
\hline Unilateral retinoblastoma & $33(97)$ & $20(100)$ & \multirow[t]{2}{*}{0.63} & $53(98)$ \\
\hline Bilateral retinoblastoma & $1(3)$ & $0(0)$ & & $1(2)$ \\
\hline \multicolumn{5}{|l|}{ Genetic testing } \\
\hline Somatic mutation & $22(65)$ & $15(75)$ & \multirow[t]{3}{*}{0.63} & $37(69)$ \\
\hline Germline mutation & $7(21)^{a}$ & $2(10)$ & & $9(17)^{\mathrm{a}}$ \\
\hline Not available & $5(15)$ & $3(15)$ & & $8(15)$ \\
\hline
\end{tabular}

Figures in parentheses are percentages or median and range. Bold values indicate significant $p$ values. IAC, intra-arterial chemotherapy; IvitC, intravitreal chemotherapy. ${ }^{a}$ One patient had $13 \mathrm{q}$ deletion syndrome.

group $\mathrm{E}$ eyes has improved significantly to $73 \%$ in the IvitC era (2012-2015) compared to $25 \%$ in the era of IAC alone (2008-2012) [6]. However, the prior study did not directly compare outcomes in eyes requiring IvitC to those treated with IAC alone. Herein, we report our 5 -year experience with IAC in the IvitC era, comparing tumor control and globe salvage in eyes treated with IAC alone versus IAC plus IvitC.

\section{Methods}

Medical records were reviewed to identify retinoblastoma patients treated at a single center (Wills Eye Hospital, Thomas Jefferson University, Philadelphia, PA, USA) during the IvitC era from January 1, 2012 through November 30, 2017. Patients treated with unilateral IAC as primary therapy were included. IAC technique and exclusion criteria have been described previously [2]. Patients were excluded if primary treatment took place at another facility, IAC was used as secondary therapy, or treatment was not complete by November 30, 2017. Institutional Review Board approval was obtained, and this study is in compliance with the Health Insurance Portability and Accountability Act.
Complete ophthalmic examination of both eyes was performed for all patients prior to treatment with IAC. The patients underwent monthly examination under anesthesia during the course of treatment, including anterior segment evaluation, fundus evaluation with indirect ophthalmoscopy, B scan ultrasonography, RetCam (Clarity, Pleasanton, CA, USA) fundus photography, and, as needed, fluorescein angiography and optical coherence tomography. Examination under anesthesia intervals were extended after tumor control was achieved.

Data were retrospectively collected following review of clinical and photographic records. Collected data included patient demographics (age, sex, race, laterality, and hereditary pattern); tumor features (largest basal diameter, thickness, location, presence of subretinal seeds, vitreous seeds, retinal detachment, and ICRB group); IAC treatment parameters (drug, dosage, number of cycles, and dates of administration); and IvitC treatment parameters (drug, dosage, number of injections, and dates of administration). Treatment outcomes included tumor control, globe salvage, life salvage, metastasis, and visual acuity.

JMP statistical analysis software (JMP Pro 13.0.0, Cary, NC, USA) was used to perform $t$ test and Fisher's exact test. Demographics, tumor features, treatment parameters, and outcomes were compared between patients treated with IAC alone versus those treated with IAC plus IvitC. 
Table 2. Clinical features at diagnosis

\begin{tabular}{|c|c|c|c|c|}
\hline & $\begin{array}{l}\text { Primary IAC } \\
\text { alone } \\
(n=34)\end{array}$ & $\begin{array}{l}\text { Primary IAC } \\
\text { with IvitC } \\
(n=20)\end{array}$ & $p$ values & $\begin{array}{l}\text { Total patients } \\
(n=54)\end{array}$ \\
\hline \multicolumn{5}{|l|}{ ICRB classification } \\
\hline Group B & $2(6)$ & $0(0)$ & \multirow[t]{4}{*}{0.42} & $2(4)$ \\
\hline Group C & $3(9)$ & $0(0)$ & & $3(6)$ \\
\hline Group D & $17(50)$ & $13(65)$ & & $30(56)$ \\
\hline Group E & $12(35)$ & $7(35)$ & & $19(35)$ \\
\hline Mean number of tumors per eye & $1(1,1-1)$ & $1(1,1-2)$ & 0.10 & $1(1,1-2)$ \\
\hline Mean largest diameter, $\mathrm{mm}$ & $18(20,10-24)$ & $18(18,13-24)$ & 0.96 & $18(18,10-24)$ \\
\hline Mean thickness, $\mathrm{mm}$ & $10(10,4-18)$ & $9(10,4-14)$ & 0.49 & $10(10,4-18)$ \\
\hline Mean distance to optic nerve, $\mathrm{mm}$ & $1(0,0-10)$ & $2(1,0-10)$ & 0.02 & $1(0,0-10)$ \\
\hline Mean distance to foveola, $\mathrm{mm}$ & $1(0,0-12)$ & $3(3,0-7)$ & 0.02 & $1(0,0-12)$ \\
\hline \multicolumn{5}{|l|}{ Vitreous seeds } \\
\hline None & $23(68)$ & $2(10)$ & \multirow[t]{5}{*}{$<0.01$} & $25(46)$ \\
\hline 1 quadrant & $2(6)$ & $3(15)$ & & $5(9)$ \\
\hline 2 quadrants & $4(12)$ & $3(15)$ & & $7(13)$ \\
\hline 3 quadrants & $1(3)$ & $2(10)$ & & $3(6)$ \\
\hline 4 quadrants & $4(12)$ & $10(50)$ & & $14(26)$ \\
\hline \multicolumn{5}{|l|}{ Subretinal seeds } \\
\hline None & $13(38)$ & $7(35)$ & \multirow[t]{6}{*}{0.50} & $20(37)$ \\
\hline 1 quadrant & $6(18)$ & $3(15)$ & & $9(17)$ \\
\hline 2 quadrants & $6(18)$ & $1(5)$ & & $7(13)$ \\
\hline 3 quadrants & $3(9)$ & $2(10)$ & & $5(9)$ \\
\hline 4 quadrants & $5(15)$ & $4(20)$ & & $9(17)$ \\
\hline no view & $1(3)$ & $3(15)$ & & $4(7)$ \\
\hline \multicolumn{5}{|l|}{ Retinal detachment } \\
\hline None & $2(6)$ & $7(35)$ & \multirow[t]{6}{*}{0.07} & $9(17)$ \\
\hline$\leq 1$ quadrant & $4(12)$ & $2(10)$ & & $6(11)$ \\
\hline 2 quadrants & $6(18)$ & $1(5)$ & & $7(13)$ \\
\hline 3 quadrants & $3(9)$ & $1(5)$ & & $4(7)$ \\
\hline 4 quadrants & $18(53)$ & $7(35)$ & & $25(46)$ \\
\hline no view & $1(3)$ & $2(10)$ & & $3(6)$ \\
\hline Vitreous hemorrhage & $1(3)$ & $1(5)$ & 0.99 & $2(4)$ \\
\hline \multicolumn{5}{|l|}{ Anterior segment findings } \\
\hline Anterior chamber seeds & $0(0)$ & $1(5)$ & 0.37 & $1(2)$ \\
\hline Iris neovascularization & $1(3)$ & $0(0)$ & 0.63 & $1(2)$ \\
\hline Neovascular glaucoma & $0(0)$ & $0(0)$ & 0.99 & $0(0)$ \\
\hline \multicolumn{5}{|l|}{ Visual acuity } \\
\hline$\geq 20 / 200$ & $13(38)$ & $11(55)$ & \multirow[t]{2}{*}{0.27} & $24(44)$ \\
\hline$<20 / 200$ & $21(62)$ & $9(45)$ & & $30(56)$ \\
\hline
\end{tabular}

Figures in parentheses indicate percentages or median and range. Bold values indicate significant $p$ values. IAC, intra-arterial chemotherapy; IvitC, intravitreal chemotherapy; ICRB, International Classification of Retinoblastoma.

\section{Results}

There were 54 eyes of 54 patients treated with primary IAC in the IvitC era (2012-2017) at Wills Eye Hospital, Philadelphia, PA, USA. These were divided into eyes treated with primary IAC alone $(n=34)$ versus eyes treated with primary IAC plus adjuvant IvitC $(n=20)$.
Patient demographics are listed in Table 1. A comparison of eyes treated with IAC alone versus IAC plus IvitC showed no significant difference in patient sex (male: 62 vs. $65 \%, p=0.99$ ), race (Caucasian: 62 vs. $70 \%, p=0.23$ ), study eye (OD: 53 vs. $55 \%, p=0.55$ ), laterality (unilateral: 97 vs. $100 \%, p=0.63$ ), or somatic mutation (65 vs.75\%, $p=0.63)$. Mean patient age was younger in patients treated with IAC alone (17 vs. 50 months, $p=0.02$ ). 
Table 3. Treatment features and outcomes

\begin{tabular}{|c|c|c|c|c|}
\hline & $\begin{array}{l}\text { Primary IAC } \\
\text { alone } \\
(n=34)\end{array}$ & $\begin{array}{l}\text { Primary IAC } \\
\text { with IvitC } \\
(n=20)\end{array}$ & $p$ values & $\begin{array}{l}\text { Total patients } \\
(n=54)\end{array}$ \\
\hline \multicolumn{5}{|l|}{ Treatment features } \\
\hline \multicolumn{5}{|l|}{ IAC features } \\
\hline Mean number of infusions & $3.4(3,1-8)$ & $3.5(3,1-6)$ & 0.84 & $3.4(2,1-8)$ \\
\hline Melphalan only & $14(41)$ & $2(10)$ & 0.03 & $16(30)$ \\
\hline Melphalan + topotecan & $20(59)$ & $18(90)$ & & $38(70)$ \\
\hline \multicolumn{5}{|l|}{ Mean cumulative dose, $\mathrm{mg}$} \\
\hline Melphalan & $18(15,5-53)$ & $19(15,4-40)$ & 0.61 & $19(15,4-53)$ \\
\hline Topotecan & $3(3,1-7)$ & $3(3,1-6)$ & 0.23 & $3(3,1-7)$ \\
\hline \multicolumn{5}{|l|}{ IvitC features } \\
\hline Interval IAC to IvitC, months & & $4(2,0-32)$ & & $4(2,0-32)$ \\
\hline Mean number of injections & - & $6(6,2-14)$ & - & $6(6,2-14)$ \\
\hline Melphalan only & - & $12(60)$ & - & $12(22)$ \\
\hline Melphalan + topotecan & & $8(40)$ & & $8(15)$ \\
\hline \multicolumn{5}{|l|}{ Mean cumulative dose, $\mu \mathrm{g}$} \\
\hline Melphalan & - & $95(80,20-188)$ & - & $95(80,20-188)$ \\
\hline Topotecan & & $63(50,20-160)$ & & $63(50,20-160)$ \\
\hline \multicolumn{5}{|l|}{ Additional therapy used } \\
\hline Systemic chemotherapy & $1(3)$ & $3(15)$ & 0.14 & $4(7)$ \\
\hline Plaque radiotherapy & $3(9)$ & $1(5)$ & 0.99 & $4(7)$ \\
\hline \multicolumn{5}{|l|}{ Outcomes } \\
\hline Follow-up, months & $28(24,2-61)$ & $24(16,4-63)$ & 0.50 & $27(21,2-63)$ \\
\hline Tumor control & $28(82)$ & $16(80)$ & 0.99 & $44(81)$ \\
\hline \multicolumn{5}{|l|}{ Tumor control per ICRB group } \\
\hline Group B & 2 of $2(100)$ & 0 of $0(0)$ & - & 2 of $2(100)$ \\
\hline Group C & 3 of $3(100)$ & 0 of $0(0)$ & - & 3 of $3(100)$ \\
\hline Group D & 15 of $17(88)$ & 9 of $13(69)$ & 0.36 & 24 of $30(80)$ \\
\hline Group E & 8 of $12(67)$ & 7 of $7(100)$ & 0.25 & 15 of $19(79)$ \\
\hline Secondary enucleation & $7(21)$ & $7(35)$ & 0.34 & $14(26)$ \\
\hline \multicolumn{5}{|l|}{ Enucleation per ICRB group } \\
\hline Group B & 0 of $2(0)$ & 0 of $0(0)$ & - & 0 of $2(0)$ \\
\hline Group C & 0 of $3(0)$ & 0 of $0(0)$ & - & 0 of $3(0)$ \\
\hline Group D & 2 of $17(12)$ & 4 of $13(31)$ & 0.36 & 6 of $30(20)$ \\
\hline Group E & 5 of $12(42)$ & 3 of $7(43)$ & 0.99 & 8 of $19(42)$ \\
\hline Reason for enucleation & $n=7$ & $n=7$ & & $n=14$ \\
\hline Solid tumor recurrence & $3(43)$ & $0(0)$ & 0.19 & $3(21)$ \\
\hline Vitreous seed recurrence & $3(43)$ & $0(0)$ & 0.19 & $3(21)$ \\
\hline Subretinal seed recurrence & $0(0)$ & $2(29)$ & 0.46 & $2(14)$ \\
\hline New anterior chamber seeds & $0(0)$ & $2(29)$ & 0.46 & $2(14)$ \\
\hline Vitreous hemorrhage & $1(14)$ & $0(0)$ & 0.99 & $1(7)$ \\
\hline Neovascular glaucoma & $0(0)$ & $0(0)$ & 0.99 & $0(0)$ \\
\hline Persistent retinal detachment & $0(0)$ & $2(29)$ & 0.46 & $2(14)$ \\
\hline Phthisis bulbi & $0(0)$ & $1(14)$ & 0.99 & $1(7)$ \\
\hline Visual acuity of salvaged eyes & $n=27$ & $n=13$ & & $n=40$ \\
\hline$\geq 20 / 200$ & $10(37)$ & $6(46)$ & 0.73 & $16(40)$ \\
\hline$<20 / 200$ & $17(63)$ & $7(54)$ & & $24(60)$ \\
\hline Metastasis & $0(0)$ & $0(0)$ & 0.99 & $0(0)$ \\
\hline Death & $0(0)$ & $0(0)$ & 0.99 & $0(0)$ \\
\hline
\end{tabular}

Figures in parentheses are percentages or median and range. Values for cumulative dose are given for treated patients only. Bold values indicate significant $p$ values. IAC, intra-arterial chemotherapy; IvitC, intravitreal chemotherapy; ICRB, International Classification of Retinoblastoma. 
Fig. 1. Retinoblastoma managed with intra-arterial chemotherapy (IAC) alone. a Group B retinoblastoma in a 24-monthold male demonstrated tumor regression (b) following two cycles of IAC with melphalan alone. c Group D retinoblastoma with peripheral extensive subretinal fluid and seeding in a 4-month-old male showed tumor regression (d) following two cycles of IAC with melphalan alone.
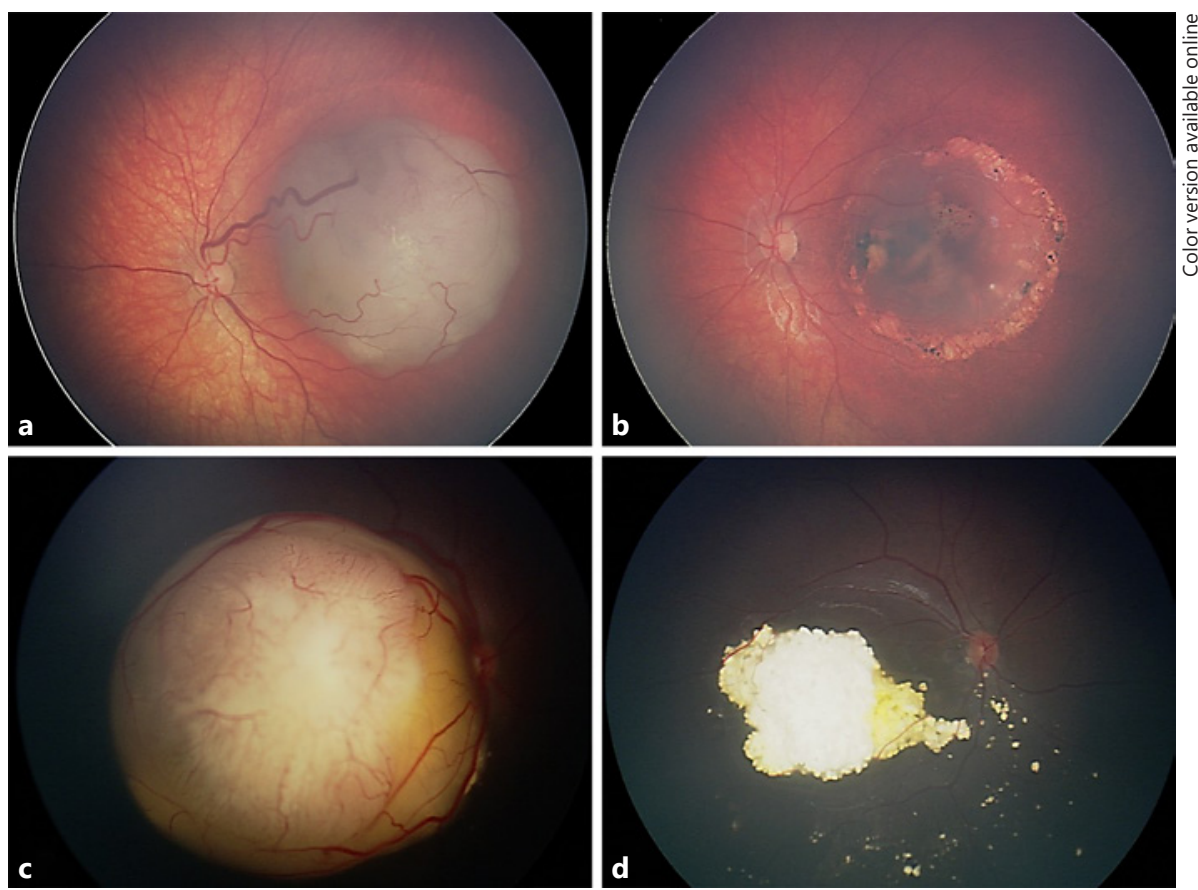

Tumor features are listed in Table 2. The ICRB group did not significantly differ in patients treated with IAC alone versus IAC plus IvitC ( $p=0.42)$, and classification included group B (6 vs. $0 \%$ ), group C ( 9 vs. $0 \%$ ), group D ( 50 vs. $65 \%$ ), or group E (35 vs. $35 \%$ ). There was no significant difference in mean largest tumor diameter (18 vs. $18 \mathrm{~mm}, p=0.96$ ), mean tumor thickness ( $10 \mathrm{vs.} 9 \mathrm{~mm}, p=$ $0.49)$, quadrants containing active subretinal seeds $(p=$ $0.50)$, quadrants of retinal detachment $(p=0.07)$, vitreous hemorrhage ( 3 vs. $5 \%, p=0.99$ ), anterior chamber seeds ( 0 vs. $5 \%, p=0.37$ ), iris neovascularization ( 3 vs. $0 \%, p=$ 0.63 ), or baseline visual acuity of $20 / 200$ or better (38 vs. $55 \%, p=0.27)$. Patients treated with IAC alone had fewer quadrants containing active vitreous seeds $(p<0.01)$.

Treatment parameters are listed in Table 3. Patients treated with IAC alone were more likely to be treated with melphalan alone ( 41 vs. $10 \%, p=0.03$ ) and less likely to receive concomitant topotecan ( 59 vs. $90 \%, p=0.03$ ). No patient was treated with topotecan alone. There was no significant difference in the mean number of IAC infusions ( 3.4 vs. $3.5, p=0.84$ ), cumulative dosage of melphalan (18 vs. $19 \mathrm{mg}, p=0.61$ ), or cumulative dosage of topotecan when used ( 3 vs. $3 \mathrm{mg}, p=0.21$ ). IvitC was administered an average of 4 months after IAC, and patients were treated with a mean of 6 injections of melphalan alone $(60 \%)$ or melphalan plus topotecan $(40 \%)$. Mean

IAC for Retinoblastoma in the Intravitreal Chemotherapy Era cumulative dosages of melphalan and topotecan were 95 and $63 \mu \mathrm{g}$, respectively.

Outcomes are listed in Table 3. Comparing patients treated with IAC alone (Fig. 1) versus IAC plus IvitC (Fig. 2), there was no significant difference in the mean length of follow-up ( 28 vs. 24 months, $p=0.50$ ), tumor control ( 82 vs. $80 \%, p=0.99$ ), secondary enucleation ( 21 vs. $35 \%, p=0.34$ ), time to enucleation (12 vs. 13 months, $p=0.78$ ), or final visual acuity of $20 / 200$ or better in salvaged eyes ( 37 vs. $46 \%, p=0.73$ ). Tumor control and globe salvage were achieved in $100 \%$ of group B and C eyes without the need for IvitC. Despite more extensive vitreous seeding in the IvitC group, there was no significant difference in tumor control for eyes treated with IAC alone versus eyes requiring IAC plus IvitC for group D ( 88 vs. $69 \%, p=0.36$ ) or group $\mathrm{E}$ ( 67 vs. $100 \%, p=0.25$ ) eyes, nor was there a significant difference in globe salvage for group $\mathrm{D}$ ( $88 \mathrm{vs.} 69 \%, p=0.36$ ) or group $\mathrm{E}$ ( $58 \mathrm{vs.}$ $57 \%, p=0.39)$. Reasons for enucleation were solid tumor recurrence ( 3 vs. $0 \%, p=0.19$ ), vitreous seed recurrence ( 3 vs. $0 \%, p=0.19$ ), subretinal seed recurrence ( 0 vs. $29 \%$, $p=0.46$ ), new anterior chamber seeds (0 vs. $29 \%, p=$ 0.46 ), vitreous hemorrhage ( 14 vs. $0 \%, p=0.99$ ), persistent retinal detachment ( 0 vs. $29 \%, p=0.46$ ), or phthisis bulbi ( 0 vs. $14 \%, p=0.99$ ). There was no metastasis or death in either group. 

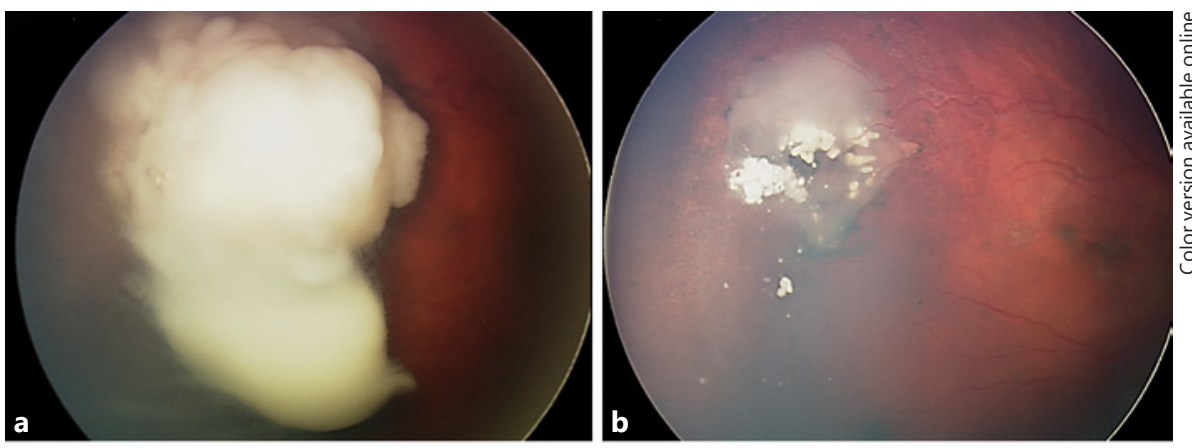

Fig. 2. Retinoblastoma managed with intra-arterial chemotherapy (IAC) plus intravitreal chemotherapy. a Group D retinoblastoma in a 24-month-old female demonstrated tumor regression (b) following one cycle of IAC with melphalan and 6 intravitreal melphalan injections. c Group $\mathrm{D}$ retinoblastoma in a 20 -month-old male showed tumor regression (d) following four cycles of IAC with melphalan and topotecan plus 6 intravitreal melphalan injections.
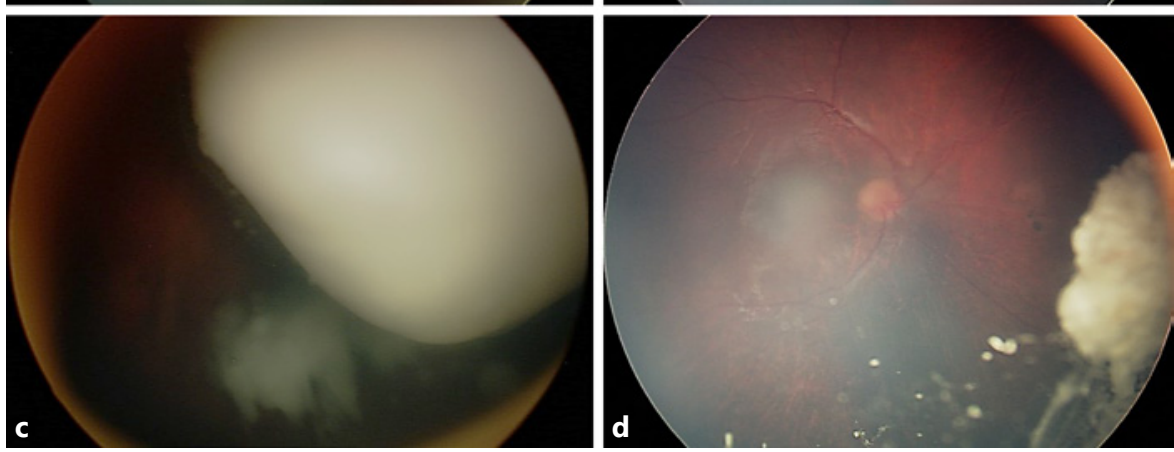

\section{Discussion}

Retinoblastoma management has changed dramatically over the past two decades $[1,7]$. New advances in local and systemic therapies have led to unprecedented rates of tumor control and globe salvage with an exceedingly low incidence of metastasis and death in developed countries [1,7]. In 1996, the introduction of systemic chemotherapy led to improved globe salvage rates for groups $\mathrm{A}, \mathrm{B}$, and $\mathrm{C}$ retinoblastoma to $90 \%$ or better $[6,7,14]$. However, globe salvage rates for group D and E eyes remained relatively poor at 47 and $23 \%$, respectively $[6,7$, $14]$. The next major breakthrough came in the late $2000 \mathrm{~s}$ with the introduction of IAC $[1,6,7]$. This improved globe salvage rates for group D eyes to nearly $80 \%$, but globe salvage for group E remained poor, with only $25 \%$ of eyes saved [2, 6]. In 2012, the introduction of IvitC dramatically changed the management for eyes with previously intractable vitreous seeds, further improving globe salvage rates, especially for group E eyes [6-13].

In this report, we describe our 5-year experience with IAC in the IvitC era and compare tumor control and globe salvage in eyes treated with IAC alone versus those requiring additional IvitC for persistent vitreous seeding. In this study, globe salvage was achieved in all group B and $\mathrm{C}$ eyes without the need for IvitC. Of 49 group D and E eyes treated with primary IAC during the studied time period, 20 eyes required additional IvitC. The clinical features of eyes requiring IvitC were similar to those of eyes treated with IAC alone with the exception of two key features, i.e., patients requiring IvitC were older (50 vs. 17 months, $p=0.02$ ) and, as expected, demonstrated a greater extent of active vitreous seeds $(p<0.01)$. Despite more extensive vitreous seeds in the IAC plus IvitC group, there was no difference in tumor control for group $\mathrm{D}$ (88 vs. $69 \%, p=0.36$ ) or group $\mathrm{E}(67$ vs. $100 \%, p=0.25)$ eyes and no difference in globe salvage for group D (88 vs. $69 \%$, $p=0.36$ ) or group E ( 58 vs. $57 \%, p=0.39$ ). No eye treated with IAC plus IvitC was enucleated for solid tumor or vitreous seed recurrence. Thus, despite the selection of eyes with more severe presenting disease, IvitC allows for comparable tumor control and globe salvage rates in eyes with extensive vitreous seeds compared to eyes requiring IAC alone. The overall globe salvage rate in this study represents an improvement compared to data reported from the pre-IvitC era (74 vs. $<60 \%)$ [6], which can be attributed to better vitreous seed management. Despite known adverse effects of IvitC on electroretinogram performance, visual acuity of salvaged eyes did not significantly differ in eyes treated with IAC alone versus IAC plus IvitC (final visual acuity of $20 / 200$ or better in 37 vs. $46 \%, p=0.73)$ [15].

Strengths of this study are the inclusion of patients treated with primary IAC only during the IvitC era at a 
single institution. Thus, this study was not complicated by crossover of patients between different treatment eras and allowed direct comparison of eyes treated with IAC alone versus those treated with IAC plus IvitC. Additionally, mean follow-up was approximately 2 years compared to mean follow-up of IvitC era patients in our prior study of 12 months [6]. Similar to our prior study, 100\% globe salvage was achieved in group $\mathrm{B}$ and $\mathrm{C}$ eyes, and $80 \%$ globe salvage was achieved for all group D eyes. Globe salvage for group E eyes was 58\%, which was slightly lower than the $73 \%$ found during the IvitC era of our prior study [6]. However, the increased length of followup could account for this difference, as the mean time to enucleation for all study patients was 13 months. Moreover, tumor control of $79 \%$ in group E eyes in this study was comparable to our prior study [6], indicating that later complications of treatment, independent of tumor control, such as persistent vitreous hemorrhage, retinal detachment, secondary glaucoma, or phthisis bulbi, could account for the difference in globe salvage.

Limitations of this study include its retrospective nature and small number of patients given the rarity of the disease and strict inclusion criteria. These data represent real-world data with treatment individualized to each patient's unique presentation. Treatment regimens for IAC for groups B, C, D, and E were comparable between groups. We recognize that compared to patients treated with IAC alone, more patients requiring IvitC received IAC with melphalan plus topotecan rather than melphalan alone $(p=0.03)$. This could have been a reflection of initial severity of disease, but this could also have contributed to increased success in patients requiring treatment with IAC plus IvitC.

These data can only be applied to eyes treated with unilateral primary IAC in the IvitC era. It is important to note that not all patients treated in this era required IAC or received IAC as primary treatment. There were no group A eyes included in this study, as group A eyes are typically managed by other less invasive means such as laser photocoagulation, thermotherapy, or cryotherapy. Some of the youngest patients with retinoblastoma could also have been excluded, since these patients often receive systemic chemotherapy as bridge therapy before proceeding with IAC if necessary [16]. Similarly, most bilateral cases were likely excluded due to primary treatment with intravenous chemotherapy. These comments document that IAC is particularly utilized in our practice for unilateral advanced retinoblastoma. Separate studies would be required to determine globe salvage rates for all eyes treated in this era.

IAC for Retinoblastoma in the Intravitreal Chemotherapy Era
In summary, IAC is a highly effective primary therapy for retinoblastoma, and IvitC is an important adjuvant for eyes with active vitreous seeds. The use of IvitC allows for comparable globe salvage rates for advanced group D and $\mathrm{E}$ eyes in which persistent vitreous seeds have previously necessitated enucleation. Tremendous strides have been made in retinoblastoma management over the past two decades that continue to improve tumor control and globe salvage rates even in advanced disease.

\section{Statement of Ethics}

Institutional Review Board approval was obtained from Wills Eye Hospital, and this study is in compliance with the Health Insurance Portability and Accountability Act (HIPAA).

\section{Disclosure Statement}

The authors have no conflicts of interest to disclose.

\section{Funding Sources}

Support was provided in part by the Eye Tumor Research Foundation, Philadelphia, PA, USA (C.L.S.), an unrestricted grant from Research to Prevent Blindness, Inc. (L.A.D.), the Heed Ophthalmic Foundation (L.A.D.), a grant from the VitreoRetinal Surgery Foundation (L.A.D.), the International Council of Ophthalmology (M.K., S.S.S.), and the Himalayan Cataract Project (V.A.E.). The funders had no role in the design and conduct of the study, in the collection, analysis and interpretation of the data, and in the preparation, review or approval of the manuscript. Carol L. Shields, MD has had full access to all the data in the study and takes responsibility for the integrity of the data and the accuracy of the data analysis.

References

1 Shields CL, Lally SE, Leahey AM, Jabbour PM, Caywood EH, Schwendeman R et al. Targeted retinoblastoma management: when to use intravenous, intra-arterial, periocular, and intravitreal chemotherapy. Curr Opin Ophthalmol. 2014 Sep;25(5):374-85.

2 Shields CL, Manjandavida FP, Lally SE, Pieretti G, Arepalli SA, Caywood EH et al. Intraarterial chemotherapy for retinoblastoma in 70 eyes: outcomes based on the international classification of retinoblastoma. Ophthalmology. 2014 Jul;121(7):1453-60.

3 Shields CL, Bianciotto CG, Jabbour P, Ramasubramanian A, Lally SE, Griffin GC et al. Intra-arterial chemotherapy for retinoblastoma: report No. 1, control of retinal tumors, subretinal seeds, and vitreous seeds. Arch Ophthalmol. 2011 Nov;129(11):1399-406. 
4 Gobin YP, Dunkel IJ, Marr BP, Brodie SE, Abramson DH. Intra-arterial chemotherapy for the management of retinoblastoma: fouryear experience. Arch Ophthalmol. 2011 Jun; 129(6):732-7.

5 Abramson DH, Fabius AW, Issa R, Francis JH, Marr BP, Dunkel IJ et al. Advanced unilateral retinoblastoma: the impact of ophthalmic artery chemosurgery on enucleation rate and patient survival at MSKCC. PLoS One. 2015 Dec;10(12):e0145436.

6 Shields CL, Alset AE, Say EA, Caywood E, Jabbour P, Shields JA. Retinoblastoma Control With Primary Intra-arterial Chemotherapy: Outcomes Before and During the Intravitreal Chemotherapy Era. J Pediatr Ophthalmol Strabismus. 2016 Sep;53(5):275-84.

7 Shields CL, Fulco EM, Arias JD, Alarcon C, Pellegrini M, Rishi P et al. Retinoblastoma frontiers with intravenous, intra-arterial, periocular, and intravitreal chemotherapy. Eye (Lond). 2013 Feb;27(2):253-64.

8 Francis JH, Abramson DH, Gaillard MC, Marr BP, Beck-Popovic M, Munier FL. The classification of vitreous seeds in retinoblastoma and response to intravitreal melphalan. Ophthalmology. 2015 Jun;122(6):1173-9.
9 Francis JH, Marr BP, Abramson DH. Classification of vitreous seeds in retinoblastoma: correlations with patient, tumor, and treatment characteristics. Ophthalmology. 2016 Jul;123(7):1601-5.

10 Berry JL, Shah S, Bechtold M, Zolfaghari E, Jubran R, Kim JW. Long-term outcomes of Group D retinoblastoma eyes during the intravitreal melphalan era. Pediatr Blood Cancer. 2017 Dec;64(12):e26696.

11 Ghassemi F, Shields CL, Ghadimi H, Khodabandeh A, Roohipoor R. Combined intravitreal melphalan and topotecan for refractory or recurrent vitreous seeding from retinoblastoma. JAMA Ophthalmol. 2014 Aug;132(8): 936-41.

12 Shields CL, Douglass AM, Beggache M, Say EA, Shields JA. Intravitreous chemotherapy for active vitreous seeding from retinoblastoma: outcomes after 192 consecutive injections. The 2015 Howard Naquin Lecture. Retina. 2016 Jun;36(6):1184-90.
13 Shields CL, Manjandavida FP, Arepalli S, Kaliki S, Lally SE, Shields JA. Intravitreal melphalan for persistent or recurrent retinoblastoma vitreous seeds: preliminary results. JAMA Ophthalmol. 2014 Mar;132(3):31925.

14 Shields CL, Mashayekhi A, Au AK, Czyz C, Leahey A, Meadows AT et al. The International Classification of Retinoblastoma predicts chemoreduction success. Ophthalmology. 2006 Dec;113(12):2276-80.

15 Francis JH, Schaiquevich P, Buitrago E, Del Sole MJ, Zapata G, Croxatto JO et al. Local and systemic toxicity of intravitreal melphalan for vitreous seeding in retinoblastoma: a preclinical and clinical study. Ophthalmology. 2014 Sep;121(9):1810-7.

16 Gobin YP, Dunkel IJ, Marr BP, Francis JH, Brodie SE, Abramson DH. Combined, sequential intravenous and intra-arterial chemotherapy (bridge chemotherapy) for young infants with retinoblastoma. PLoS One. 2012; 7(9):e44322. 